\title{
Disturbed anal sphincter function following vaginal delivery
}

\author{
J M Wynne, J L Myles, I Jones, R Sapsford, R E Young, A Hattam, S E Cantamessa
}

\begin{abstract}
Background-Recently interest in idiopathic (neurogenic) faecal incontinence has swung from denervation of the external anal sphincter to the internal sphincter.

Aims-To evaluate the effects of vaginal delivery on the internal sphincter.

Subjects-1372 mothers were studied antenatally and 1202 were accepted into the study.
\end{abstract}

Methods-Sphincter pressures were measured antenatally, in the early postnatal period, and six to 10 weeks later in selected patients.

Results-755 of 1202 subjects assessed antenatally were primiparous women and 447 multiparous women. Some 320 previous spontaneous vaginal deliveries (SVD) (mean $59 \mathrm{~mm} \mathrm{Hg}$ ) and 67 previous forceps deliveries (mean $58 \mathrm{~mm} \mathrm{Hg}$ ) had lower resting pressures than 755 primiparous women (mean $66 \mathrm{~mm} \mathrm{Hg}$ ) $(p<0.01)$. A total of 493 subjects were reassessed postnatally. There were 372 SVDs, 47 vacuum extractions, 20 forceps, and 54 caesarean deliveries. All vaginal deliveries but not caesarean sections dropped their resting anal pressures from antenatal values $(p<0 \cdot 001)$. Some 227 first SVDs had a much greater fall than 145 subsequent SVDs. In 162 subjects who had undergone their first vaginal delivery and who were followed up there was some recovery but the resting pressures were still lowered at six to 10 weeks post partum.

Conclusions-The first vaginal delivery causes a permanent lowering of resting anal pressures. The possible reasons for this are discussed.

(Gut 1996; 39: 120-124)

Keywords: anal sphincter function, vaginal delivery, autonomic neuropathy.

Bowel and bladder disorders are among the most common problems seen in clinical practice. Aetiological factors that might contribute

TABLE I Antenatal anal pressure readings (1202 subjects)

\begin{tabular}{lclll}
\hline Group & Number & $\begin{array}{l}\text { Resting pressures } \\
(\mathrm{mm} \mathrm{Hg})\end{array}$ & $\begin{array}{l}\text { Squeeze pressures } \\
(\mathrm{mm} \mathrm{Hg})\end{array}$ & $\begin{array}{l}\text { Anal length } \\
(\mathrm{cm})\end{array}$ \\
\hline Previous caesarean sections only & 32 & $64(16)$ & $\mathbf{7 4}(48)$ & 3.08 \\
Primiparous women & 755 & $66(19)$ & $\mathbf{8 7}(46)$ & 3.03 \\
Previous SVD & 320 & $59(16)^{\star}$ & $78(47)^{\star}$ & 3.05 \\
Previous vacuum assisted delivery & 28 & $62(16)$ & $78(48)$ & 3.20 \\
Previous forceps assisted delivery & 67 & $58(18)^{\star}$ & $62(34)^{\star}$ & 3.07 \\
\hline
\end{tabular}

${ }^{{ } \mathrm{p}<0.01}$ when compared with primiparous women (two tailed Mann-Whitney and unpaired $t$ test). Data shown as mean (SD). to this spectrum of related disorders deserve close attention.

Injury to the striated muscle of the pelvic floor, particularly the external anal sphincter during vaginal delivery is well recognised and may be a consequence of direct injury to the muscle $^{1}$ or due to a traction injury to the pudendal and sacral nerves that supply the pelvic floor. ${ }^{2-5}$ This denervation has been implicated in the aetiology of idiopathic faecal incontinence, ${ }^{67}$ urinary stress incontinence, and vaginal prolapse. ${ }^{8}$

Weakness of the internal anal sphincter is also a feature of idiopathic faecal incontinence and studies ${ }^{9} 10$ indicate the likelihood that there is denervation of the internal sphincter. A demonstrable effect of vaginal delivery on the autonomic system is therefore of importance. Freckner and Euler ${ }^{11}$ showed that the external sphincter contributed $15 \%$ to the resting pressure. In an earlier study in our hospital Myles ${ }^{12}$ noted a fall in resting pressures after vaginal delivery that was greater than $15 \%$. These subjects are included in this report. Cali et al ${ }^{13}$ noted that resting pressures were lower in multiparous than nulliparous women and postulated that there was an injury to the autonomic nerves during parturition. Sultan et $a^{1}$ using endorectal ultrasound observed a disruption of the internal sphincter or the external sphincter after vaginal delivery in $37 \%$ of subjects. Disruption of the internal sphincter was associated with a greater fall in resting pressure. Whether there is also an injury to the autonomic nerves in the pelvis during vaginal delivery remains an open question. This paper reports observations of changes in the anal resting pressure in a large group of women following parturition.

\section{Methods}

\section{Subjects}

A total of 1372 subjects attending the antenatal clinic at the Mater Mothers Hospital in Brisbane between February 1991 and May 1994 had sphincter pressures measured as part of a screening programme to monitor the effect of vaginal delivery on the pelvic floor. In 1202 subjects (Table I) adequate data were available and criteria for acceptance of the readings were met. Their ages ranged from 15 years to 42 years (mean 26). Some 755 were primiparous and 447 were multiparous women. Of the multiparous women, 67 had had at least one forceps delivery; 28 a previous vacuum delivery; 320 unassisted spontaneous vaginal deliveries (SVD), and 32 only a caesarean section. 
TABLE II Early postnatal anal resting pressures (493 subjects)

\begin{tabular}{lclllll}
\hline & & & & & \multicolumn{2}{c}{ Change $>20 \%$} \\
\cline { 3 - 7 } Group & & & & & \\
\hline Caesarean sections & 54 & $71(23)$ & $67(20)$ & $4(26)(-2 \%) \ddagger$ & $14(26 \%)$ & $16(30 \%)$ \\
First SVD & 227 & $68(19)$ & $54(19)^{\star}$ & $13(22)(15 \%) \dagger$ & $113(50 \%)$ & $26(11 \%)$ \\
Subsequent SVD & 145 & $59(15)$ & $54(19)^{\star}$ & $6(19)(5 \%)$ & $47(32 \%)$ & $21(14 \%)$ \\
Vacuum assisted delivery & 47 & $70(19)$ & $50(19)^{\star}$ & $20(25)(24 \%) \dagger$ & $30(64 \%)$ & $8(17 \%)$ \\
Forceps assisted delivery & 20 & $70(16)$ & $49(20)^{\star}$ & $21(18)(31 \%) \dagger$ & $14(70 \%)$ & $0(0 \%)$ \\
\hline
\end{tabular}

${ }^{\star} \mathrm{p}<0.001$ when comparing antenatal with postnatal pressures using the paired $t$ test.

$t p<0.01$ when comparing the fall in resting pressures of the various types of vaginal delivery with caesarean deliveries.

$\neq \mathrm{p}<0.001$ when comparing fall in resting pressure with first SVDs. Vacuum and forceps assisted vaginal deliveries when

combined were significant at the 0.05 level. Note that forceps and vacuum assisted deliveries were combined for some analyses. Data shown as mean (SD).

Four hundred and ninety three subjects were reassessed between one and five days after their delivery (see Tables II, III, IV). A total of 372 had a SVD without assistance. In 227 of these this was the first vaginal delivery. Some $145 \mathrm{had}$ had a previous vaginal delivery. Forty seven of 493 subjects had vaginal delivery assisted using a vacuum extractor and 20 required forceps assistance. Four of the subjects in the vacuum extraction group previously had vaginal deliveries but none of the 20 forceps deliveries. Fifty four subjects underwent a caesarean section.

Two hundred and thirty two subjects who had undergone a vaginal delivery with or without assistance were reassessed six to 10 weeks later. They were selected because of a greater than $50 \%$ fall in their squeeze pressures or a $1 \mathrm{~cm}$ or greater fall in the level of their perineums when straining compared with antenatal values. This was part of the protocol for an extended study. One hundred and sixty two of these subjects (see Table V) had not previously undergone a vaginal delivery and were evaluated for recovery of their resting pressures.

\section{Apparatus}

The apparatus consisted of a Model 43-212 Baxter pressure monitoring transducer (Baxter Health Care Corporation, Edwards Critical Care Division, Irvine, CA 92714-5686, USA) attached to an amplifier, which was linked to a digital display. Measuring was performed using a $6 \mathrm{~mm}$ St Mark's balloon mounted on a size 8 Portex intravenous catheter (Boots Pharmaceutical) connected to the pressure transducer. The filling pressure for the balloon was set to $30 \mathrm{~cm}$ water. The system was then calibrated in a pressure bottle.

\section{Technique}

Patients were assessed in the lateral position with a small box placed next to the anus to support the transducer. The probe was introduced deep into the rectum and then withdrawn slowly. The point at which basal rectal pressures started to rise was taken as the upper end of the anal canal. Resting and maximum squeeze pressures were recorded every $0.5 \mathrm{~cm}$ along the anal canal. A recording made at the anal verge was considered as the zero reading. Squeeze pressures were calculated by subtracting the resting pressures from the maximum squeeze pressures.

\section{Statistical methods}

Results between groups were evaluated using both an unpaired two tailed $t$ test and a two tailed Mann-Whitney test. Postnatal results were compared with antenatal results using the paired $t$ test.

Ethical approval was obtained from the University of Queensland Ethics Committee and the Mater Mothers Hospital Ethics Committee.

\section{Results}

Antenatal resting pressures (Table I)

Three hundred and twenty subjects who had undergone previous SVDs and 67 who had undergone previous forceps deliveries had lower resting pressures than 755 subjects who were primigravida. Thirty two multigravida who had undergone only previous caesarean sections did not differ from 755 primigravida. Elective caesarean sections did not differ from caesarean sections performed after the patient had entered labour. Twenty eight who had undergone previous vacuum extractions fell in between and did not differ significantly from other groups.

There were no differences between 210,80 , and 30 subjects who had undergone respectively one, two, and more than two previous SVDs. One hundred and eighty seven subjects under 30 years of age who had undergone only previous SVDs were not different from 133 similar subjects 30 years and older. There were no differences between 84,548 , and 123 primiparous women aged less than 20 years, 20 to 29 years, and 30 or over. Increasing gestation did not change resting pressures.

Antenatal squeeze pressures (Table I)

Squeeze pressures were lower in subjects who had undergone previous vaginal and forceps deliveries when compared with primigravida.

\section{Manometric antenatal anal length (Table I)}

There was no difference seen in subjects who had undergone previous vaginal deliveries when compared with primigravida.

\section{Early postnatal resting pressures (Table II)}

All the vaginally delivered groups, comprising 227 first SVDs, 145 subsequent SVDs, 47 
TABLE III Early postnatal anal squeeze pressures (493 subjects)

\begin{tabular}{lcccc}
\hline Group & Number & $\begin{array}{c}\text { Antenatal } \\
(\mathrm{mm} \mathrm{Hg})\end{array}$ & $\begin{array}{c}\text { Postnatal } \\
(\mathrm{mm} \mathrm{Hg})\end{array}$ & $\begin{array}{l}\text { Fall } \\
(\mathrm{mm} \mathrm{Hg})\end{array}$ \\
\hline Caesarean sections & 54 & $108(55)$ & $112(71)$ & $-4(-5 \%)$ \\
First SVD & 227 & $95(43)$ & $54(35)^{\star}$ & $41(38 \%) \dagger$ \\
Subsequent SVD & 145 & $93(49)$ & $63(41)^{\star}$ & $30(26 \%) \dagger \neq$ \\
Vacuum assisted delivery & 47 & $96(41)$ & $47(36)^{\star}$ & $49(46 \%) \dagger$ \\
Forceps assisted delivery & 20 & $114(58)$ & $36(26)^{\star}$ & $78(69 \%) \dagger \neq 0$ \\
\hline
\end{tabular}

${ }^{\star} \mathrm{p}<0.0001$ comparing antenatal with postnatal readings (paired $t$ test).

tp $<0.001$ comparing with caesarean sections.

$\neq \mathrm{p}<0.05$ comparing with first SVDs.

$\mathrm{Sp}<0.05$ comparing with vacuum deliveries. Data shown as mean (SEM).

vacuum extractions, and 20 forceps deliveries dropped their resting pressures immediately following vaginal delivery. The group comprising 54 women who underwent caesarean sections showed no change in their resting pressures. There was no difference in the change in resting pressure when comparing 15 elective caesarean sections, 33 caesarean sections performed during the first stage of labour, and six caesarean sections performed during the second stage of labour. First vaginal deliveries whether spontaneous or assisted sustained a greater fall in resting pressures than caesarean deliveries and subsequent vaginal deliveries. In first unassisted vaginal deliveries the fall in resting pressures was double that following subsequent vaginal deliveries. Forceps and vacuum assisted deliveries fell more than first unassisted vaginal deliveries.

While the overall resting pressures fell after vaginal deliveries there was considerable variation in each group. In $32 \%$ to $70 \%$ of vaginal deliveries resting pressures fell by greater than $20 \%$ of their antenatal values. With the exception of forceps deliveries, between $11 \%$ and $17 \%$ of vaginal deliveries increased their resting pressures by more than $20 \%$ immediately post partum. Caesarean deliveries showed equal changes in both directions.

\section{Early postnatal squeeze pressures (Table III)}

We confirmed large falls in squeeze pressures after all forms of vaginal delivery but not after caesarean sections. First vaginal deliveries fell $12 \%$ more than subsequent deliveries. Forceps fell $31 \%$ more than first deliveries and $23 \%$ more than vacuum assisted deliveries.

TABLE IV Early postnatal manometric anal length (342 patients)

\begin{tabular}{lcll}
\hline Group & Number & Antepartum & Postpartum \\
\hline Caesarean sections & 54 & $3.06(0 \cdot 7)$ & $3 \cdot 18(0 \cdot 56)$ \\
First SVD & 227 & $3.09(0 \cdot 62)$ & $3 \cdot 01(0 \cdot 62)$ \\
Subsequent SVD & 145 & $3 \cdot 21(0 \cdot 57)$ & $3 \cdot 08(0 \cdot 66)^{\star}$ \\
Vacuum extractions & 47 & $3 \cdot 15(0 \cdot 55)$ & $2 \cdot 87(0 \cdot 69)^{\star}$ \\
Forceps deliveries & 20 & $3 \cdot 25(0 \cdot 79)$ & $2 \cdot 90(0 \cdot 80)$
\end{tabular}

${ }^{\star} \mathrm{p}<0.05$ comparing antenatal with postnatal readings (paired $t$ test). Data shown as mean (SEM)

TABLE V Follow up data for selected first vaginal deliveries (162 subjects)

\begin{tabular}{llll}
\hline & $\begin{array}{l}\text { Resting pressures } \\
(\mathrm{mm} \mathrm{Hg})\end{array}$ & $\begin{array}{l}\text { Squeeze pressures } \\
(\mathrm{mm} \mathrm{Hg})\end{array}$ & $\begin{array}{l}\text { Anal length } \\
(\mathrm{cm})\end{array}$ \\
\hline Antenatal & $69 \cdot 2(16)$ & $105 \cdot 0(52)$ & $3 \cdot 15(0.59)$ \\
Postnatal & $51 \cdot 3(18)^{\star}$ & $44.5(31)$ & $2.95(0.63)^{\star}$ \\
Follow up & $62 \cdot 6(17)^{\star} \dagger$ & $78.6(43)^{\star} \dagger$ & $3 \cdot 18(0.53) \dagger$ \\
\hline
\end{tabular}

${ }^{\star} \mathrm{p}<0.001$ compared with antenatal readings (paired $t$ test).

tp $<0.001$ compared with postnatal readings (paired $t$ test). Data shown as mean SEM).
Anal length early post partum (Table IV)

Manometric anal length fell very slightly $(0 \cdot 13$ $\mathrm{cm})$ but significantly $(\mathrm{p}<0.01)$ in all vaginally delivered subjects. Within individual groups this was only significant $(p<0.05)$ for subsequent vaginal deliveries and forceps deliveries.

Follow up resting pressures (Table V)

One hundred and sixty two subjects undergoing their first vaginal delivery including those assisted by vacuum extraction or forceps were tested again six to 10 weeks later to assess recovery. Most of these subjects had sustained a lowering of the pelvic floor or severe fall in squeeze pressures and were participants in an ongoing study of therapeutic measures to strengthen the pelvic floor post partum. In this subgroup resting pressures of $69.2 \mathrm{~mm} \mathrm{Hg}$ antepartum fell to $51.3 \mathrm{~mm} \mathrm{Hg}$ after vaginal delivery. There was improvement to $62.6 \mathrm{~mm}$ $\mathrm{Hg}$ at the six to 10 week follow up, but the pressures were still lowered when compared with antenatal figures.

\section{Follow up squeeze pressures (Table V)}

In the 162 subjects undergoing their first vaginal delivery tested six to 10 weeks post partum the squeeze pressures that fell from $105 \mathrm{~mm} \mathrm{Hg}$ to $44.5 \mathrm{~mm} \mathrm{Hg}$ early post partum, recovered partially to $78.6 \mathrm{~mm} \mathrm{Hg}$ at the follow up assessment.

\section{Follow up manometric anal length (Table V)}

Manometric anal length fell from $3.15 \mathrm{~cm}$ antenatally to $2.95 \mathrm{~cm}$ early postnatally in this selected group of first vaginal deliveries. By follow up the length had returned to antenatal values measuring $3 \cdot 18 \mathrm{~cm}$.

\section{Discussion}

Several authors ${ }^{235}$ have centred attention on injuries and denervation of the external anal sphincter following vaginal delivery emphasising the implications of this for the later development of faecal incontinence. ${ }^{67}$ More recently interest has swung to a deficient internal anal sphincter as an important contributor to faecal incontinence where an associated autonomic neuropathy has been demonstrated. ${ }^{914-18}$ In addition, disturbance of the autonomic nervous system as well as of spinal reflexes through the sacral cord have been demonstrated in patients suffering bowel and bladder disorders. ${ }^{15} 1920$ The association of autonomic and somatic denervation in faecal incontinence points to a common aetiology. Resting pressure drops $50 \%$ on sympathetic blockade. ${ }^{21}$ Cali et al ${ }^{13}$ have suggested that an autonomic denervation contributes to a fall in resting anal pressures following vaginal delivery. Sultan et $a l^{1}$ have shown occult disruption of the internal anal sphincter in $35 \%$ of vaginal deliveries and linked this to a fall in resting pressures. The question of a concomitant injury to the autonomic nerves in the pelvis remains open. 
Our study has confirmed that in addition to a fall in squeeze pressure following vaginal delivery there is also a fall in the resting anal pressure. This fall in resting pressures was most noticeable in patients undergoing their first vaginal delivery and was minimal in subsequent vaginal deliveries. Assisted vaginal deliveries whether by vacuum extraction or forceps resulted in a greater fall in resting pressures and the number who dropped their pressures was greater.

Our findings may be explained by the finding of Sultan et al ${ }^{1}$ that direct injuries to the sphincters occurred predominantly during first deliveries, especially forceps deliveries. They found that the sphincter defect with its lowered resting pressure persisted at six weeks and six months. Their ultrasound study showed that injuries occurred to both internal and external anal sphincters. In our study we detected a shortening of anal length but this was more noticeable in multiparous women. While there was an overall fall in resting pressures, $11 \%$ to $17 \%$ of vaginal deliveries increased their pressures by over $20 \%$, suggesting a variable and more complex response to parturition.

Cali et $a l^{13}$ used a radial eight port water filled catheter. They found that multiparous women had lower resting pressures than nulliparous women. As there was no asymetry they considered that this was probably caused by injury to the sympathetic nervous system rather than to disruption of the internal sphincter. This conclusion was disputed by Sultan and $\mathrm{Kamm}^{22}$ who had found occult injuries to the internal sphincter using ultrasound in 35\% of primiparous deliveries. In our series of 1202 subjects tested antenatally there was a small but highly significant difference in resting pressures between women who had undergone previous vaginal delivery and those who had not. This was not related to the number of vaginal deliveries nor to increasing age. This suggests that the first vaginal delivery has permanent consequences for the internal sphincter.

Measurements of anal length are more subject to interobserver error than other manometric assessments and may vary from day to day in the same patient. ${ }^{23} \mathrm{We}$ observed a small but significant fall of $0.2 \mathrm{~cm}$ in anal length following vaginal delivery with a full recovery at six to 10 weeks follow up. Unlike the fall in resting pressures this was significant in multiparous but not in primiparous women. We did not find a reduction in manometric anal length when comparing primigravida with parous women in the subjects seen antenatally. These findings must be considered in the light of the finding by Sultan et al $^{1}$ of a subclinical rupture of the internal or external anal sphincters, or both, in a proportion (37\%) of subjects having vaginal deliveries. We did not have facilities to perform ultrasonography on our subjects. We suggest that an associated injury to the autonomic system during vaginal delivery might explain some of these findings and would contribute to our understanding of the spectrum of disorders affecting the hindgut and urinary system in women.
In support of this hypothesis we note that Carlstedt et al $^{24}$ showed that stimulation of the presacral sympathetic nerves resulted in both contraction and relaxation of the internal anal sphincter and this seemed to be dependent on the nature of the electrical stimulus used. When the sympathetic supply along the periarterial lumbar colonic nerves was stimulated contraction only occurred. Epidural anaesthesia when used to block the sympathetic discharge lowered the resting pressure in the anal canal. They concluded that there were either inhibitory motor fibres in the presacral nerves or that stimulation of afferent fibres in the presacral nerves might inhibit internal sphincter action by activating spinal reflexes. Durdey et al $^{10}$ found that the resting pressures in patients whose innervation to the internal sphincter had been transected during restorative proctocolectomy fell to the same value as that in subjects with neurogenic faecal incontinence. Bouvier et $a^{25}$ showed that autonomic reflexes mediated via afferent pathways originating in the bladder region, and passing with the sympathetic system both inhibited and stimulated the internal anal sphincter. They concluded that the reflexes occurred both at the lumbar spinal level and at the inferior mesenteric ganglion. They consider that these reflexes participate in regulating urinary bladder and internal anal sphincter activity. It is quite possible, therefore, that the response of the internal anal sphincter to an injury to afferent or efferent presacral nerves, or both, during vaginal delivery would have a variable effect on resting pressures and manometric anal canal length.

Meagher et $a l^{26}$ have demonstrated autonomic nerve fibres passing from the presacral plexus across the retrorectal space to the rectum from S1 to S4. Some branches were large. Rectal prolapse both internal and external is frequently found in subjects with disordered defecation and with changes in the internal and external sphincters. This association invites the hypothesis that during the second stage of delivery the fetal head can exert traction on the rectum and that this can be avulsed from its attachments to the sacrum. The presacral nerves are avulsed injuring the presacral plexus. The lateral ligaments are stretched. Speakman et $a l^{27}$ found that surgical division of the lateral ligaments during surgery for rectal prolapse was associated with postoperative constipation.

In conclusion we have shown a significant fall in resting pressure following vaginal delivery when compared with antenatal values. Our findings are not fully explained by direct injury to the sphincter muscles. Lowered resting pressure antenatally in women who have born children vaginally indicate that the effect is not transitory. The question as to whether direct injury to the internal sphincter is the only cause of the fall in resting pressure is unresolved. Differing patterns of injury to the autonomic nerves offer a plausible explanation for the occurrence of internal sphincter denervation in neurogenic faecal incontinence as well as many bowel and bladder disorders in women. It also explains their frequent association. At this 
stage such a theory is still conjectural and convincing evidence is lacking.

This study was supported by a grant from the National Health and Medical Research Council.

1 Sultan AH, Kamm MA, Hudson CN, Thomas JM, Bartram CI. Anal-sphincter disruption during vaginal delivery. N Engl f Med 1993; 329: 1905-11.

2 Snooks SJ, Swash M, Henry MM, Setchell M. Risk factors in childbirth causing damage to the pelvic floor innervation. Int $\Im$ Colorect Dis 1986; $1: 20-4$.

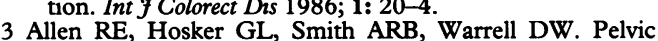
floor damage and childbirth: a neurophysiology study. Br F Obstet Gynaecol 1990; 97: 770-9.

4 Small KA, Wynne JM. Evaluating the pelvic floor in obstetric patients. Aust NZ $\mathcal{F}$ Obstet Gynaecol 1990 30: 41-5.

5 Sultan AH, Kamm MA, Hudson CN. Pudendal nerve damage during labour: prospective study before and after childbirth. Brf Obstet Gynaecol 1994; 101: 22-8.

6 Parkes AG, Swash M, Urich H. Sphincter denervation in anorectal incontinence and rectal prolapse. Gut 1977; 18: 656-65.

7 Kiff ES, Swash M. Slowed conduction in the pudendal nerves in idiopathic (neurogenic) faecal incontinence. $\mathrm{Br} \mathcal{F}$ Surg 1984; 71: 614-6.

8 Smith ARB, Hosker GL, Warrell DW. The role of partial denervation of the pelvic floor in the aetiology of genitourinary prolapse and stress incontinence of urine. A neurophysiological study. Br f Obstet Gynaecol 1989; 96: 24-8.

9 Lubowski DZ, Nicholls RJ, Burleigh DE, Swash M. Internal anal sphincter in neurogenic fecal incontinence. Gastroenterology 1988; 95: 997-1002.

10 Durdey P, Coller JA, Barrett DJ, Schoetz DJ Jr. Is reduction in resting pressure in neurogenic faecal incontinence due to denervation of the internal sphincter. (Abstract) Int $\mathcal{F}$ to denervation of the internal

11 Frenckner $\mathrm{B}, \mathrm{v}$ Euler $\mathrm{Chr}$. Influence of pudendal block on the function of the anal sphincters. Gut $1975 ; 16: 482-9$.

12 Myles JL. Pelvic floor denervation: is it reversible? [Thesis] Queensland: University of Queensland, 1991.

13 Cali RI, Blatchford GJ, Perry RE, Pitsch RM, Thorson AG, Christensen MA. Normal variation in anorectal manometry. Dis Colon Rectum 1992; 35: 1161-4.
14 Sun WM, Read NW, Donnelly TC. Impaired internal anal sphincter function in a subgroup of patients with anal sphincter function in a subgroup of patients with idiopathic

15 Bannister J, Read NW, Donnelly TC, Sun WM. External and internal anal sphincter responses to rectal distension in normal subjects and in patients with idiopathic faecal incontinence. Br $\mathcal{F}$ Surg 1989; 76: 617-21.

16 Speakman CTM, Kamm MA. The internal anal sphincter new insights into faecal incontinence. Gut 1991; 32: 345-6.

17 Sun WM, Read NW, Miner PB. Relation between rectal sensation and anal function in normal subjects and patients with faecal incontinence. Gut 1990; 31: patients

18 Speakman CTM, Kamm MA. Abnormal visceral autonomic innervation in neurogenic faecal incontinence. Gut 1993; 34: 215-21.

19 Kerrigan DD, Lucas MG, Sun WM, Donnelly TC, Read NW. Idiopathic constipation associated with impaired urethrovesical and sacral reflex function. Br $\mathcal{F}$ Surg 1989; 76: 748-51.

20 Kamm MA, Leonnard-Jones JE. Rectal mucosal electrosensory testing - evidence for a rectal sensory neuropathy in idiopathic constipation. Dis Colon Rectum 1990; 33: 419-23.

21 Frenckner B, Ihre T. Influence of autonomic nerves on the internal sphincter in man. Gut 1976; 17: 306-12.

22 Sultan AH, Kamm MA. Relationship between parity and anal manometry. Dis Colon Rectum 1993; 36: 783.

23 Eckhardt VF, Elmer T. Reliability of anal pressure measurements. Dis Colon Rectum 1991; 34: 72-7.

24 Carlstedt A, Nordgren S, Fasth S, Appelgren L, Hultén L. Sympathetic nervous influence on the internal anal sphincter and rectum in man. Int $\mathcal{F}$ Colorect Dis 1988; 3: 90-5.

25 Bouvier M, Grimaud JC, Salducci J, Gonella J. Role of vesical afferent nerve fibres involved in the control of internal anal sphincter motility. F Auton Nerv Syst 1984; 10: $243-5$.

26 Meagher AP, Adams WJ, Lubowski DZ, Vonthethoff LW. Autonomic nerves cross the posterior plane of rectal Autonomic nerves cross the posterior plane

27 Speakman CTM, Madden MV, Nicholls RJ, Kamm MA. pation but prevents recurrence: results of a prospective randomized study. Br $¥$ Surg 1991; 78: 1431-3. 